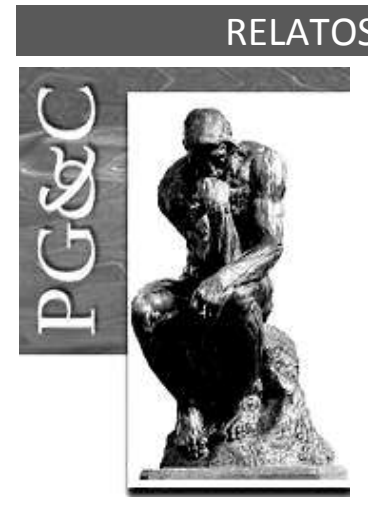

\title{
INTERATIVIDADE MÚTUA EM SITES DE PARQUES CIENTÍFICOS, TECNOLÓGICOS E DE INOVAÇÃO PARA GERAÇÃO DE CAPITAL SOCIAL
}

\author{
Sicilia Vechi Gonçalves \\ Doutoranda em Engenharia e Gestão do Conhecimento pela Universidade \\ Federal de Santa Catarina, Brasil. \\ E-mail: sicilia.vechi@gmail.com \\ Clarissa Stefani Teixeira \\ Doutora em Engenharia de Produção pela Universidade Federal de Santa \\ Catarina, Brasil. Professora da Universidade Federal de Santa Catarina, \\ Brasil. \\ E-mail: clastefani@gmail.com \\ Márcio Vieira de Souza \\ Doutor em Engenharia de Produção pela Universidade Federal de Santa \\ Catarina, Brasil. Professor da Universidade Federal de Santa Catarina, \\ Brasil. \\ E-mail: marciovieiradesouza@gmail.com

\section{Neri dos Santos} \\ Doutor em Ergonomie de l'Ingenierie pelo Conservatoire National des Arts \\ et Métiers, França. Professor da Universidade Federal de Santa Catarina, \\ Brasil. \\ E-mail: nerisantos@gmail.com
}

\begin{abstract}
Resumo
O objetivo deste artigo é identificar a abertura para interatividade mútua em áreas de conteúdo periódico dos sites de 30 Parques Científicos Tecnológicos e de Inovação em operação no Brasil, levantando as contribuições de interação para a geração de capital social. A pesquisa exploratória e descritiva com abordagem qualitativa analisa as ocorrências de campos interativos vinculados ao conteúdo dos sites. $\mathrm{O}$ estudo mostrou que a maior parte destes combina interatividade mútua e áreas de notícias, em espaços para comentários ou por direcionamento em hiperlinks para as mídias sociais. Falta de atualização e monitoramento de mídias sociais e erros de hiperlink foram observados como possíveis entraves à interação mútua e bloqueio à geração de capital social cognitivo e relacional. Os Parques são ambientes de fomento à inovação e dependem da criação do conhecimento. Com a dinâmica da comunicação digital em rede e uso crescente da inteligência coletiva, para gerar inovação, os Parques devem manter presença digital ativa na produção, atualização e monitoramento de mídias, propiciando o novo conhecimento e as relações dele decorrentes.
\end{abstract}

Palavras-chave: Interatividade mútua. Sites. Parques. Capital social.

\section{MUTUAL INTERACTIVITY IN SITES OF SCIENTIFIC, TECHNOLOGICAL AND INNOVATION PARKS FOR THE GENERATION OF SOCIAL CAPITAL}

\section{Abstract}

The objective of this article is to identify the openness to mutual interactivity in areas of periodic content of the sites of 30 Technological Science and Innovation Parks in operation in Brazil, raising the interaction

Perspectivas em Gestão \& Conhecimento, João Pessoa, v. 9, n. 2, p. 112-127, maio/ago. 2019. DOI: http://dx.doi.org/10.21714/2236-417X2019v9n2p112

http://periodicos.ufpb.br/ojs2/index.php/pgc. ISSN: 2236-417X. Publicação sob Licença (cc) EY-NC-ND 
contributions for the generation of social capital. Exploratory and descriptive research with a qualitative approach analyzes the occurrences of interactive fields linked to the content of the sites. The study showed that most of these sites combines mutual interactivity and news areas, in comment spaces or by targeting hyperlinks to social media. Lack of updating and monitoring of social media and hyperlink errors were observed as possible obstacles to mutual interaction and blocking the generation of cognitive and relational social capital. Parks are environments that foster innovation and depend on the creation of knowledge. With the dynamics of digital network communication and increasing use of collective intelligence, in order to generate innovation, the Parks must maintain active digital presence in the production, updating and monitoring of media, providing the new knowledge and the relationships derived from it.

Keywords: Mutual interactivity. News. Sites. Parks. Social capital.

\section{INTRODUÇÃO}

Com a mudança do paradigma econômico da sociedade industrial para a sociedade do conhecimento, do século XIX ao XXI, os ambientes de inovação representam o advento do conhecimento científico como um motor de desenvolvimento socioeconômico. (FERRARI; GASPARINDO; RISOLA, 2013). Parques como complexos planejados para o desenvolvimento científico, tecnológico e de inovação são reconhecidos pela legislação no Brasil como espaços de estímulo à capacitação de empresas, à competitividade industrial e à sinergia de pesquisa, recursos tecnológicos e cultura inovadora.

Para impulsionar a inovação e a competitividade, os habitats estimulam práticas de cooperação pela criação de espaços de consenso (ARANHA, 2008) para integrar os atores da Tríplice Hélice, como governo, indústria e universidades (ETZKOWITZ, 2009). A partir da comunicação, esses ambientes têm na disseminação de conteúdos em seus sites e mídias sociais alguns canais de estímulo à cooperação e integração desses atores e da sociedade, possibilitando a geração de capital social em rede.

No trato das informações que disponibilizam, os Parques potencializam o capital social quando a informação oferece pertinência, usabilidade e confiabilidade para chamar a atenção de um indivíduo, acionar sua capacidade de refletir e de recombinar novas e antigas informações. Este processo de recombinação "está na origem da produção de conhecimento individual que, ao ser compartilhado coletivamente, dá origem ao capital social" (CASTILHO, 2015, p. 63-64).

Além disso, há relação direta entre a inovação inerente à missão dos habitats e a criação do novo conhecimento. Segundo Nonaka e Takeuchi, esta decorre, em linhas gerais, da interação entre indivíduos que compartilham conhecimento tácito entre si, em um ciclo de conversão de que culmina com a produção de novo conhecimento, o qual vai ganhando escala para ser incorporado pela organização (NONAKA; TAKEUCHI, 1997).

Este trabalho foi elaborado para identificar a abertura à interatividade mútua em áreas de conteúdos periódicos dos sites de Parques Científicos, Tecnológicos e de Inovação brasileiros em operação e levantar as contribuições desse tipo de interação para a geração de capital social.

Mais do que uma interatividade reativa, em que o humano reage à máquina em simples relação de estímulo e resposta, a pesquisa aborda o conceito e a verificação de campos que propiciem a interação mútua, aquela em que os ambientes digitais permitem relações humanas interdependentes, envolvendo negociação, participação, construção inventiva e cooperada da relação mútua (PRIMO, 2007, p. 62).

O presente estudo reúne fundamentação teórica sobre parques e sua presença digital para a inovação, distinções entre interação e interatividade na mediação de conteúdos

Perspectivas em Gestão \& Conhecimento, João Pessoa, v. 9, n. 2, p. 112-127, maio/ago. 2019. 
e o capital social em rede. Após o delineamento da metodologia de pesquisa, os resultados e discussões apontam para as áreas de notícias nos sites de Parques, os campos de comentários, o direcionamento por hiperlink para redes sociais, as redes apontadas e a atualização de seus conteúdos. Por fim, as considerações finais levantam contribuições e tendências para futuras pesquisas.

\section{FUNDAMENTAÇÃO TEÓRICA}

Nesta seção apresenta-se a fundamentação teórica que deu subsídio para a análise, contemplando: Parques e presença digital para inovação; interação e interatividade na mediação de conteúdo por esses habitats e capital social em rede a partir dos sites.

\subsection{Parques e presença digital para inovação}

O conceito de Parque ligado a arranjo tecnológico e de inovação surgiu nos anos de 1950, em Stanford, na Califórnia, Estados Unidos, com o Stanford Research Park, baseando-se na interação entre universidade e iniciativa privada. Os Parques têm por objetivo promover uma infraestrutura técnica, logística e administrativa para apoiar empresas no desenvolvimento de seus produtos, aumentar a competitividade, favorecer a transferência tecnológica e a gerar um ambiente propício à inovação (MCTI, 2014).

O marco histórico para as primeiras menções aos Parques no Brasil foi a criação do Programa do Conselho Nacional de Desenvolvimento Científico e Tecnológico (CNPq), em 1984, que alavancou as primeiras iniciativas, juntamente com as incubadoras de empresas, nas cidades de São Carlos (SP), Florianópolis (SC), Curitiba (PR), Campina Grande (PB) e no Distrito Federal (DF). Relatório ABDI e ANPROTEC (2008) demonstra que, enquanto no ano de 2000 havia 10 propostas de parques, em 2007 eram 74 empreendimentos. Em 2013, o Ministério da Ciência Tecnologia e Inovação (MCTI, 2014) identificou 94 parques científicos e tecnológicos existentes, nas etapas de planejamento, implantação e operação.

Nesse contexto, uma definição oficial de Parque no Brasil é dada pela Lei no 13.243 , de 11 de janeiro de 2016, que dispõe sobre estímulos ao desenvolvimento científico, à pesquisa, à capacitação científica e tecnológica e à inovação. De acordo com o artigo 10, Parque é um:

[...] complexo planejado de desenvolvimento empresarial e tecnológico, promotor da cultura de inovação, da competitividade industrial, da capacitação empresarial e da promoção de sinergias em atividades de pesquisa científica, de desenvolvimento tecnológico e de inovação, entre empresas e uma ou mais ICTs, com ou sem vínculo entre si (BRASIL, 2016).

Os Parques assumem os mais diversos modelos de composição e atuação e se tornam redes complexas, diferentes entre si em seus formatos e funções, tornando difícil muitas vezes a distinção ou enquadramento em categorias (ADÁN, 2012). Parques que podem ser denominados Científicos, Tecnológicos, Científicos e Tecnológicos ou de Inovação, têm características em comum como aglomeração de empresas de tecnologia inovadoras e de capital especializado, universidades e centros de pesquisa.

Nesta era pós-industrial, o conhecimento é visto como a matéria-prima mais valorizada, a fonte de vantagem competitiva duradoura para as empresas, diante de uma economia de incerteza e rápidas mudanças (NONAKA; TAKEUCHI, 2008). Os ambientes de Parques, concebidos para fomentar as soluções inovadoras envolvendo diferentes setores da sociedade, dependem do que Nonaka e Takeuchi (2008) definem como a criação do novo conhecimento organizacional. Esta é fomentada pela conversão cíclica do conhecimento tácito

Perspectivas em Gestão \& Conhecimento, João Pessoa, v. 9, n. 2, p. 112-127, maio/ago. 2019. 
individual em conhecimento explícito que pode ser incorporado aos processos e à cultura de uma organização. E a conversão dos conhecimentos tem início pela interação entre pessoas, na fase da socialização, seja em ambiente físico ou virtual. Tais argumentos reforçam a necessidade de uma presença digital dos Parques como geradores de inovação.

\subsection{Interação e interatividade na mediação de conteúdo pelos Parques}

A noção de interatividade é diretamente associada aos novos meios de comunicação digital, como os jogos eletrônicos e a TV interativa e, por vezes, remete ao conceito de uma interação técnica entre humano e máquina. Recuero (2009) ressalta que um site interativo deve oferecer muito mais do que a possibilidade reativa de clicar, mas favorecer uma interação mútua, construída, negociada e criativa. Lemos (1997) justifica esta demanda pelo surgimento das novas formas de circulação da informação, em oposição ao modelo um-todos da mídia tradicional e em face do novo modelo todos-todos, em que a comunicação é individualizada, personalizada e em tempo real.

Recuero (2009) ressalta que essas novas formas de auto-organização, baseadas na interação e na comunicação, exigem das organizações a capacidade de adaptação nas redes sociais, a fim de que "exista circularidade nessas informações, para que os processos sociais coletivos possam manter a estrutura social e as interações possam continuar" (RECUERO, 2009, p.89).

O surgimento dos sites de redes sociais foi um passo além na evolução da internet. São definidos por Boyd e Ellison (2007) como sistemas que permitem a construção de um perfil ou página pessoal com interação por meio de comentários e exposição ao público dessas páginas de cada usuário. São, portanto, softwares destinados à comunicação mediada pelo computador.

A necessidade dos usuários de compartilhar conteúdos e da criação de novas ferramentas tecnológicas marca o advento do termo web 2.0, a segunda geração da rede mundial de computadores. Desta fase, destaca-se a criação de páginas pessoais, a interação direta entre os usuários e o protagonismo destes na produção de conteúdos como forma de expressão (TELLES, 2010).

Salaverría e Negredo (2009) argumentam que a audiência para quem se produz e media conteúdos não é a mesma de 10 anos antes. O conceito unidirecional de informação, no qual o veículo fala e a audiência apenas escuta, não representa mais a relação existente entre o produtor e o consumidor dos conteúdos. Jornalistas, fontes, o público e as instituições, como os Parques, têm um papel redefinido nesse contexto, sendo que os profissionais da informação e da mídia tradicional, como os jornalistas, não são mais voz uníssona na produção. A relevância da participação dos leitores na produção de conteúdos é não apenas reconhecida, como coordenada e estimulada pelos jornais em seus sites e nas redes sociais.

A produção, atualização e mediação de conteúdos no ambiente digital podem ser realizadas pelas próprias instituições, independentemente da atuação de meios de comunicação tradicionais. Neste caso, destaca-se a relevância da atualidade para qualquer veículo noticioso, como um critério de noticiabilidade originado do jornalismo que se refere ao produto informativo. Este critério aponta que notícias devem se referir a acontecimentos 0 mais próximo possível do momento da publicação. A atualidade, associada ao critério da frequência das publicações, atribui periodicidade à produção informativa, pela qual o leitor obtém "o quadro de referência em que os acontecimentos do mundo são captados" (WOLF, 1999, p. 91). O autor acrescenta ainda que a determinação de atualidade para a operação de cada veículo de comunicação tem a influência de fatores como a existência ou não de concorrência.

Perspectivas em Gestão \& Conhecimento, João Pessoa, v. 9, n. 2, p. 112-127, maio/ago. 2019. 


\subsection{Capital social em rede a partir dos sites}

Castells (2007) aponta que a expansão acelerada das redes sociais virtuais alterou significativamente a interatividade entre membros de uma comunidade, gerando reflexos no capital social. $\mathrm{O}$ aumento da diversidade de ambientes informativos na internet surge em consonância com a diversidade das redes virtuais estruturadas.

A geração de capital social a partir dos sites de redes sociais recebeu uma classificação de Recuero (2009), a partir dos estudos de Bertolini e Bravo (2001) sobre a estrutura das redes sociais. Do ponto de vista dos indivíduos e do que eles podem adquirir, considera-se o capital social relacional (relativo aos laços sociais), o capital social normativo (normas e valores de determinado grupo), o capital social cognitivo (referente à soma do conhecimento e das informações colocados pelo grupo), a confiança no ambiente social por parte dos indivíduos e o capital social institucional (conhecimento das regras de interação e onde o nível de interação é alto).

O contexto da produção de conteúdos por qualquer pessoa ou instituição que tenha interesse abre campo para o estudo da interatividade digital como um fenômeno social e não apenas técnico. Para Outing (1998) é necessária a compreensão de que a base da interação é a de uma conversa: "um processo cíclico em que dois atores, alternadamente, ouvem, pensam e falam" (1998, p.5), ou seja, trata-se de um processo de troca, de mutualidade.

No mesmo sentido, baseados nas teorias da Comunicação, Primo e Cassol (1999) caracterizam a chamada interação mútua, em que os atores participam de uma construção inventiva, em relação de cooperação, afetando-se mutuamente em meio aos processos de negociação. Os mesmos autores afirmam que o foco dos estudos de interatividade deve estar na ação entre pessoas, e não partir do que o computador pode ofertar para que a interação aconteça. Ou seja, a relação em si é mais importante do que a ação do emissor ou do receptor da informação. Ela vai sendo definida durante o processo interativo pelos participantes, diferentemente da interação reativa, em que as possibilidades de escolha do usuário ficam limitadas pelas opções que a interface disponibiliza.

\section{PROCEDIMENTOS METODOLÓGICOS}

O presente estudo trata-se de uma pesquisa descritiva exploratória, com informações qualitativas a respeito dos espaços de interatividade nos sites de Parques brasileiros em operação, para a geração de capital social com base na interação mútua (DUARTE et al., 2005; PRIMO, 2007).

Foram identificados para a pesquisa os 30 Parques brasileiros em fase de operação, a partir do benchmarking de Teixeira et. al. (2015). A exemplo da pesquisa destes autores, o presente estudo adota amostra extraída de publicação do Ministério da Ciência Tecnologia e Inovação (MCTI, 2014), na ausência de uma listagem oficial de Parques em operação na web com endosso da Associação Nacional de Entidades Promotoras de Empreendimentos Inovadores (ANPROTEC).

Para todos os Parques listados foi realizada a pesquisa dos sites oficiais por meio do buscador Google. Sendo assim, os Parques descritos neste estudo são aqueles que disponibilizavam sítio on-line próprio na ocasião da consulta. O Quadro 1 apresenta os 30 habitats de inovação em operação no Brasil analisados:

Perspectivas em Gestão \& Conhecimento, João Pessoa, v. 9, n. 2, p. 112-127, maio/ago. 2019. 
Sicilia Vechi Gonçalves et al.

Quadro 1 - Parques brasileiros analisados

\begin{tabular}{|c|c|}
\hline Parques & Municípios \\
\hline Parque de Ciência e Tecnologia Guamá & Belém \\
\hline Parque Tecnológico da Bahia & Salvador \\
\hline Parque Tecnológico do NUTEC & Fortaleza \\
\hline Parque Tecnológico da Paraíba & Campina Grande \\
\hline Porto Digital & \multirow{2}{*}{ Recife } \\
\hline Parque Tecnológico Eletro-eletrônica de Pernambuco & \\
\hline Sergipe Parque Tecnológico - SergipeTec & Aracaju \\
\hline Parque Tecnológico de Belo Horizonte & Belo Horizonte \\
\hline Parque Tecnológico de Uberaba & Uberaba \\
\hline Parque Tecnológico Universidade Federal do Rio de Janeiro & \multirow{2}{*}{ Rio de Janeiro } \\
\hline Polo de Biotecnologia Bio-Rio & \\
\hline Parque Tecnológico da Região Serrana & Petrópolis \\
\hline Parque Tecnológico Botucatu & Botucatu \\
\hline Parque Tecnológico de Ribeirão Preto & Ribeirão \\
\hline Parque Tecnológico de São Carlos & São Carlos \\
\hline Parque Tecnológico de São José dos Campos & \multirow{2}{*}{ São José dos Campos } \\
\hline Parque Tecnológico UNIVAP & \\
\hline Parque Tecnológico de Sorocaba & Sorocaba \\
\hline Parque Empresarial Techno Park & Campinas \\
\hline Parque Tecnológico Itaipu & Foz do Iguaçu \\
\hline Curitiba Tecnoparque & Curitiba \\
\hline Parque Científico e Tecnológico da PUCRS & Porto Alegre e Viamão \\
\hline Parque Científico e Tecnológico Regional TecnoUnisc & Santa Cruz do Sul \\
\hline Parque Tecnológico de São Leopoldo - TecnoSinos & São Leopoldo \\
\hline Parque Tecnológico do Vale dos Sinos & Campo Bom \\
\hline Ulbratech & Canoas \\
\hline Parque de Inovação Tecnológica de Joinville e Região & Joinville \\
\hline Parque Científico e Tecnológico do Extremo Sul Catarinense & Criciúma \\
\hline ParqTec Alfa & \multirow{2}{*}{ Florianópolis } \\
\hline Sapiens Parque & \\
\hline
\end{tabular}

Fonte: Adaptado de Teixeira et al. (2015)

Após a localização dos endereços eletrônicos, foram estabelecidas as referências para a coleta de dados. O levantamento focalizou as áreas de interação mútua, termo defendido por Primo (2007), que podem ser contextualizadas na diferenciação com a interação reativa. Cabe explicitar o conceito de interatividade digital (LEMOS, 1997), assim como os de interação mútua e interação reativa dentro desse contexto, para melhor compreensão sobre a pesquisa.

Interatividade digital:

Perspectivas em Gestão \& Conhecimento, João Pessoa, v. 9, n. 2, p. 112-127, maio/ago. 2019. 
[...] diálogo entre homens e máquinas (baseadas no princípio da microeletrônica), através de uma 'zona de contato' chamada de 'interfaces gráficas', em tempo real. A tecnologia digital possibilita ao usuário interagir, não mais apenas com o objeto (a máquina ou a ferramenta), mas com a informação, isto é, com o "conteúdo” (LEMOS, 1997, online).

Interação mútua "é aquela caracterizada por relações interdependentes e processos de negociação, em que cada interagente participa da construção inventiva e cooperada da relação, afetando-se mutuamente" (PRIMO, 2007, p. 62).

Interação reativa: "é limitada por relações determinísticas de estímulo e resposta" (PRIMO, 2007, p. 62).

Primo (2000) relata que um interagente humano não navegará somente por um ou por outro modo de interação na web, pois sistemas ou sites que se apresentam em modo fechado, somente com abertura para a interação reativa, podem disponibilizar link que direciona a um chat onde o interagente humano possa debater com outros, estabelecendo-se, então, uma interação mútua. É o caso das homepages e notícias dos sites sem áreas abertas à publicação de comentários, mas que oferecem links de direcionamento aos sites de redes sociais.

A confirmação dessas ocorrências na presente pesquisa conduziu este estudo à verificação e análise das áreas de comentários disponibilizadas pelos sites junto às notícias, quando o site oferecia tal seção, e também dos hiperlinks disponíveis nas homepages que encaminhavam para os sites de redes sociais dos Parques. A análise, portanto, considerou áreas em que os conteúdos são atualizados periodicamente.

A pesquisa desconsiderou formulários disponibilizados nas abas de contato dos sites, que aparecem isoladamente e restringem a interação, seja pela ausência de conteúdos vinculados que possam caracterizar a interação como diálogo, seja pela não publicação pelos sites do que ali é registrado pelo usuário.

A etapa de consulta aos sites dos Parques foi realizada nos dias 25 e 26 de agosto de 2015, analisando:

a) Ocorrência de áreas de notícias nos sites oficiais dos parques brasileiros;

b) Ocorrência de campos para comentários junto às notícias;

c) Existência de hiperlinks na primeira página dos sites (homepage) para o direcionamento dos usuários a sites de redes sociais, com teste dos hiperlinks de direcionamento;

d) Identificação dos sites de redes sociais indicados;

e) Verificação sobre a atualização de conteúdos das redes sociais citadas na data da pesquisa e em dias anteriores.

$\mathrm{Na}$ busca pelos dos sites dos Parques em operação no Brasil, levantou-se que cinco habitats não possuíam endereço próprio na ocasião da pesquisa e apenas eram mencionados em páginas de outras instituições. Foram eles o Parque Tecnológico Eletro-eletrônica de Pernambuco (ParqTel), o Parque Tecnológico de Ribeirão Preto, o Curitiba Tecnoparque, o ParqTec Alfa e o Parque Científico e Tecnológico Regional TecnoUnisc. Diante da dificuldade de enquadrá-los nos critérios adotados para esta pesquisa, os cinco foram desconsiderados.

$\mathrm{Na}$ etapa de análise, o estabelecimento de categorias, segundo Gomes (1994), foi utilizado para, a partir das ocorrências, estabelecer os elementos relacionados entre si ou com características em comum, auxiliando na descoberta e descrição dos resultados.

Após a coleta de dados e a análise, foi realizada uma busca na literatura sobre interatividade e a geração do capital social. Esta etapa foi realizada a partir das descobertas obtidas nos exemplos coletados e, portanto, estas são diretamente relacionadas a autores que

Perspectivas em Gestão \& Conhecimento, João Pessoa, v. 9, n. 2, p. 112-127, maio/ago. 2019. 
já trataram destes exemplos, razão pela qual eventuais citações com referência avançam à área dos resultados, levantando diálogo que pode vir a se estabelecer na pesquisa qualitativa.

Dentre os vários conceitos discutidos, os estudos de Recuero (2009) trazem à luz a vertente sobre o capital social que será considerada nesta pesquisa. Em primeiro lugar, "refere-se a um valor constituído a partir das interações e entre os atores sociais" (p.45). Com base nos construtos de diversos autores, Recuero sintetiza:

Consideraremos o capital social como um conjunto de recursos de um determinado grupo (recursos variados e dependentes de sua função (...)) que pode ser usufruído por todos os membros do grupo, ainda que individualmente, e que está baseado na reciprocidade (...). Ele está embutido nas relações sociais e é determinado pelo conteúdo delas. (RECUERO, 2009, p.50).

A próxima seção apresenta os resultados e discussões decorrentes dos dados coletados e analisados.

\section{RESULTADOS E DISCUSSÕES}

O presente estudo procurou identificar a abertura para interatividade mútua em áreas de conteúdos periódicos dos sites de Parques Científicos, Tecnológicos e de Inovação brasileiros e levantar as contribuições desse tipo de interação para a geração do capital social. $\mathrm{Na}$ categorização dos aspectos relevantes da pesquisa, serão tratadas as categorias das áreas de notícias nos sites de Parques; os campos de comentários; os hiperlinks de direcionamento às redes sociais; as redes sociais utilizadas e a atualização dos conteúdos publicados nas redes sociais.

\section{1 Áreas de notícias nos sites de Parques}

Sob a ótica da geração do capital social, Castilho (2015, p. 44) pontua que "notícia é um tipo específico de dado cuja principal característica é o seu ineditismo, tendo como atributos indispensáveis a relevância, pertinência e confiabilidade".

Dos 25 sites pesquisados de Parques Científicos, Tecnológicos e de Inovação brasileiros em operação, $80 \%$ contam com áreas de notícias e $20 \%$ contam somente com áreas institucionais. As seções de notícias veiculam conteúdos utilizando tipologias jornalísticas, produzidas periodicamente pelos próprios Parques ou por terceiros. Nas listas de notícias observadas, os conteúdos se relacionam com as áreas de atuação dos Parques ou abrangem temas voltados à inovação e às novas tecnologias. Entre os 20 sites com áreas de notícias, $75 \%$ as exibem na homepage do Parque, permitindo que o leitor acompanhe já na primeira página a frequência de atualização do site. A constatação converge com uma característica essencial da dinâmica do jornalismo: a manutenção da atualidade das notícias publicadas, combinada com a frequência de publicações situa o leitor sobre a periodicidade de produção de uma mídia (WOLF, 1999).

Os sites que indicam em sua primeira página apenas o hiperlink que redireciona o leitor a uma nova seção representam $25 \%$. Se a área de notícias em um site de Parque científico, tecnológico ou de inovação não enfrenta a concorrência direta de um veículo de comunicação tradicional, ela tem ao menos o desafio de capturar a atenção dos públicos de interesse dos Parques, no cenário de abundante informação que é a web. Ao adotar a atualidade e manter o mais visível possível a frequência da produção de conteúdos com esta

Perspectivas em Gestão \& Conhecimento, João Pessoa, v. 9, n. 2, p. 112-127, maio/ago. 2019. 
finalidade, o parque proporciona ao visitante do site a referência temática e temporal necessária para que ele se torne um leitor e passe a interagir com as informações existentes.

\subsection{Campos para comentários}

Ao analisar as ferramentas de interatividade mútua disponibilizadas pelos sites de Parques, verificou-se que apenas $16 \%$ dos 25 Parques pesquisados apresentam abertura para comentários de usuários em suas páginas. São eles o Parque Tecnológico de Uberaba (MG), o Parque Tecnológico da Região Serrana (RJ), o Parque de Inovação Tecnológica de Joinville (SC) e o Parque Científico e Tecnológico do Extremo Sul Catarinense (SC).

Nos casos verificados, quando disponíveis, os espaços se encontram ao final das notícias publicadas e permitem que a contribuição dos usuários permaneça exibida. Uma informação aparente nesses campos é a solicitação dos dados de identificação do usuário como condição para a participação: nome e e-mail.

Ao todo são 21 os sites que não oferecem o recurso, o que representa $84 \%$ da amostragem. A falta de espaços para comentários nas áreas de notícias não condiz com a importância destacada por diversos autores consultados no presente estudo (RECUERO; PRIMO; LEMOS; OUTING; SALAVERRIA; NEGREDO) para a iniciativa de interatividade. Para Outing (1998) um site realmente interativo deve facilitar a comunicação entre os seres humanos. Ele exemplifica citando que sites jornalísticos plenamente interativos precisam desse mecanismo de feedback do leitor, que deve ser publicado abaixo das reportagens ou em área especialmente destinadas à publicação das opiniões do leitor.

Recuero (2009), no reforço da classificação de Bertolini e Bravo (2001), argumenta que áreas de comentário do leitor em blogs permitem a geração de capital social relacional, que fortalece os laços entre um grupo de pessoas e compreende "a soma das relações, laços e trocas que conectam os indivíduos de uma determinada rede" (RECUERO 2009, p.50-51). Ou seja, quanto mais a parte coletiva do capital social se fortalece nas interações dos indivíduos, mais fácil é a apropriação individual desse capital. É, por exemplo, quando o autor de blog ou blogueiro baseia-se nos comentários da rede para selecionar novos conteúdos a partir deles.

\subsection{Hiperlinks de direcionamento a redes sociais}

Os hiperlinks são como portas virtuais que abrem caminho a outras informações na internet (LEMOS, 1997). Eles encaminham o usuário aos hipertextos, informações textuais que são combinadas com imagens (fotos, vídeos, ilustrações) e sons organizados para proporcionar uma navegação não-linear, sem hierarquização e com a oferta de possibilidades de leitura à escolha do leitor (FERRARI, 2010).

Entre os 25 sites de parques pesquisados, $64 \%$ oferecem caminhos que remetem à interatividade fora do endereço oficial, a partir de links de direcionamento para páginas de redes sociais. Analisando em partes, $44 \%$ dos sites direcionam o usuário para três sites de redes sociais, $19 \%$ encaminham para 4 redes e, igualmente, 19\% para 2 redes. Ao todo, $12 \%$ direcionam o usuário por links a 5 ou mais redes sociais e um site (6\%) direciona para apenas uma rede.

Do ponto de vista da interatividade, o direcionamento do leitor por meio de um hiperlink a outro site configuraria o clique como uma interação reativa (PRIMO, 2007). Entretanto, esse mesmo clique pode ser analisado no contexto desta pesquisa de outro modo: como um encaminhamento do usuário ao site de uma rede social, que é o campo escolhido pela organização para as interações mútuas entre comunidades de usuários.

Quanto mais diversos são os insumos informativos não estruturados, maior a riqueza do produto final para a geração do capital social (POLANYI, 1996). Nos sites de Parques, o

Perspectivas em Gestão \& Conhecimento, João Pessoa, v. 9, n. 2, p. 112-127, maio/ago. 2019. 
direcionamento terceiriza o ambiente virtual do diálogo com o leitor para fora do endereço oficial, mas também absorve os sites de mídias sociais como extensões permanentes, o que, de certo modo, garante a oportunidade de interações. Tal consideração levou este estudo à verificação dos hiperlinks e dos mais citados sites de redes sociais, bem como sua atualização.

Ao tratar da interatividade de hiperlinks ou navegação proativa, Sims (1999) explica que a mesma ocorre quando diversos links são colocados à disposição do usuário, para que ele navegue como quiser. Este caso, entretanto, exige esforço da equipe do site, garantindo a manutenção dos links ativos para que estejam sempre acessíveis. Do contrário, se houver links fora de funcionamento ou não permitidos, conforme chegou a ser observado neste estudo, conforme a subseção a seguir, o usuário pode tornar-se desmotivado a interagir.

\subsection{Sites de redes sociais apontados}

Na pesquisa realizada nos sites de Parques, Facebook, Twitter e YouTube foram os sites de redes sociais encontrados com maior frequência, conforme indica o Gráfico 1:

Gráfico 1 - As redes sociais para as quais sites de Parques direcionam o usuário

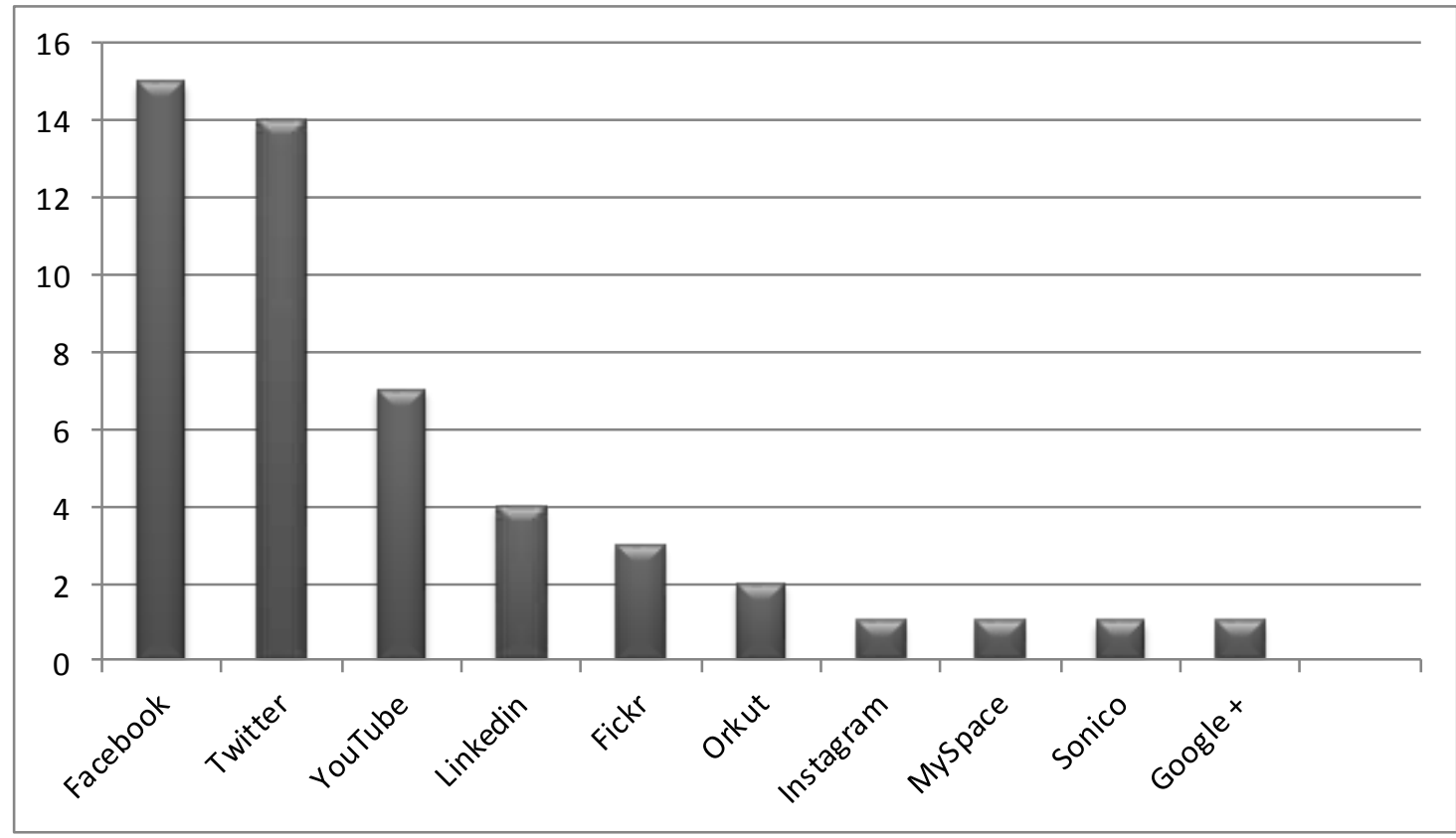

Fonte: Dados da pesquisa (2016)

Durante a navegação pelos links válidos, foi possível identificar falta de atualização no direcionamento feito por alguns sites. Um exemplo é a disponibilização de links feita pelo Parque Tecnológico da Paraíba e o Parque Tecnológico da Região Serrana para a rede social Orkut, extinta ${ }^{1}$ pela companhia Google em setembro de 2014. Outras ocorrências comuns foram os erros de direcionamento dos links de redes sociais, que interrompem a navegação e o acesso à página indicada. Durante o levantamento, cinco links com o mesmo problema foram localizados, o que representa $10 \%$ dos 50 links de direcionamento para redes sociais disponíveis nas homepages dos sites de Parques e testados para este estudo.

1 Notícia do site G1, divulgada em 30 de setembro de 2014. Disponível em: http://g1.globo.com/tecnologia/noticia/2014/09/orkut-sai-do-ar-nesta-terca-acesso-chega-7-dosinternautas-no-brasil.html. Acesso em 20 de jun 2019.

Perspectivas em Gestão \& Conhecimento, João Pessoa, v. 9, n. 2, p. 112-127, maio/ago. 2019. 
Antes mesmo do advento das mídias sociais como o Facebook, Outing (1998) reforçava o potencial de interatividade nos sites pessoais, modelo que já foi utilizado por alguns veículos de comunicação para abrir espaço às publicações de seus leitores, oferecendo-lhes páginas pessoais voltadas a hobbies, fotos, carros, animais domésticos ou qualquer assunto do interesse dos usuários, como foi o caso do Florida's Sunline ${ }^{2}$.

A interatividade mútua no contexto dos sites dos Parques, por exemplo, permite, conforme as classificações consideradas neste estudo (RECUERO, 2009; BERTOLINI; BRAVO, 2001), a geração de capital social no nível do indivíduo quando fomentada por temas do interesse individual, tais quais manutenção de fóruns temáticos (laços sociais), publicação de boas práticas no ambiente inovador (normas e valores de grupo), divulgação de publicações e postagens técnicas e científicas (capital social cognitivo), apresentação de projetos de inovação social (confiança no ambiente social) e editais de geração de oportunidades (regras de interação). Enquanto os temas abordados representam ferramentas para o estabelecimento da interação, os fóruns, campos de compartilhamento e resposta são canais indispensáveis para a possibilidade de ação mútua.

Além do ponto de vista dos indivíduos, outro nível de capital social perceptível nos sites de redes sociais parte do ponto de vista de grupos, ou seja, do que é desfrutável pela coletividade, como a confiança na instituição, a presença das instituições, as relações entre as comunidades, as leis e normas e o conhecimento. Esse nível depende tanto do capital social no nível anterior, dos indivíduos, quanto de "uma sedimentação dos laços sociais, que apenas pode acontecer em relação ao tempo, com a interação estabelecida entre um grupo de pessoas" (RECUERO, 2009, p.50-51). Segundo a autora, quanto mais o nível coletivo de capital social se fortalece, mais cada indivíduo consegue se apropriar deste capital. Logo, a interação mútua fomentada nos canais digitais dos Parques científicos, tecnológicos e de inovação ajuda a constituir essa relação entre seus usuários.

\subsection{Atualização de conteúdos nas redes sociais}

Outro fator percebido durante a pesquisa foi a falta de atualização nas redes sociais para as quais os sites de Parques direcionam o usuário. Ao todo, $37,5 \%$ dos sites que fazem o direcionamento não registravam atualização nas redes sociais na data da consulta e em 14 dias anteriores. Considerando, então, este intervalo de até 15 dias para definir um prazo de atualização, entre 10 parques que disponibilizam links para redes sociais e as mantinham atualizadas, 90\% mantinham o Facebook atualizado e, 70\%, o Twitter. O YouTube e o Linkedin estavam atualizados em $10 \%$ das páginas de redes sociais dos Parques.

Se o recurso de viabilização da interatividade mútua escolhido pelos parques é o direcionamento do leitor às suas mídias sociais por meio de hiperlink, a apresentação de conteúdos atualizados nestes canais mostra ao leitor a presença digital ativa do Parque naquela mídia, estimulando a troca de informações e a geração de capital social relacional. Como afirmam Primo e Cassol (1999, p. 89), é preciso que exista circularidade nas informações nas redes sociais baseadas em interação e comunicação, de modo que interfaces plenamente interativas devem trabalhar "na virtualidade, possibilitando a ocorrência da problemática e viabilizando atualizações".

A atualização de conteúdos, como notícias e vídeos, no site do Parque responde ainda à geração de capital social cognitivo, devido ao maior apelo informacional que envolve esses conteúdos. Halavais (2002) identifica outro benefício da interatividade mútua fomentada por

\footnotetext{
${ }^{2}$ O Florida's Sunline é apontado por Primo e Cassol (1999) como jornal on-line norte-americano pioneiro na oferta do serviço de sites de hobbies dos usuários, em uma seção na qual os usuários poderiam criar páginas sobre assuntos diversos de seu interesse.
}

Perspectivas em Gestão \& Conhecimento, João Pessoa, v. 9, n. 2, p. 112-127, maio/ago. 2019. 
conteúdos atualizados no retorno dado pela audiência. Sua pesquisa mostra que autores de blogs, os blogueiros, valorizam a postagem de conteúdos novos para seus leitores e que essa percepção pode influenciar o que é publicado por esses autores. Da mesma forma, o volume de acessos ao conteúdo, os compartilhamentos e comentários produzem diversas percepções e geram padrões de publicação decorrentes das interações mútuas. É quando o capital social relacional influencia o capital social cognitivo.

Os efeitos da difusão de cada um são distintos e devem ser previstos pelos sites e sites de redes sociais dos Parques. Enquanto as informações com apelo ao capital social cognitivo tendem a ir mais longe, difundindo-se entre diferentes grupos em redes sociais, tendo como valor o ineditismo e a originalidade, o capital social relacional se reflete na rápida difusão das informações dentro de uma mesma rede social. Ali, o valor está mais ligado à replicação e ao acesso rápido de toda a rede à mesma informação (RECUERO, 2009, p.121). Atualização, monitoramento e resposta permitem aos Parques atuar para absorver esses valores.

\section{CONSIDERAÇÕES FINAIS}

O presente estudo analisou a abertura para interatividade nas áreas de conteúdo e homepages dos sites de Parques brasileiros e levantou as contribuições desse tipo de interação para a geração do capital social. A ênfase, da revisão teórica à coleta e análise de dados, foi para as áreas de interatividade mútua, que privilegiam as relações humanas mediadas por computador. A pesquisa envolveu 30 Parques brasileiros em fase de operação no ano de 2015 e identificou na web os sites oficiais. Das áreas de interação mútua observadas, foram desconsiderados os campos de formulário institucional, tendo foco apenas as áreas interativas abertas à contribuição do usuário, vinculadas a conteúdos produzidos ou compartilhados pelos Parques.

$\mathrm{Na}$ análise dos sites dos Parques Científicos, Tecnológicos e de Inovação em operação no Brasil, levantou-se que cinco entidades não possuíam site próprio e não puderam ser analisadas de acordo com os critérios da pesquisa. A maioria dos parques conta com áreas de notícias e as disponibiliza na home, primeira página do site. O fácil acesso permite que o leitor acompanhe a frequência de atualização da mídia. Os Parques que usam notícias e não as exibem na homepage direcionam o leitor para outras sessões, ocultando da primeira página os conteúdos periódicos e mais atualizados.

O formato notícia, mais utilizado pela maioria dos Parques no Brasil para a atualização de seus leitores, mostra-se como alternativa, como fator de motivação para o engajamento à interação mútua com os públicos envolvidos. Outros benefícios relacionados ao capital social nos sites de Parques emergem das publicações informativas, como fóruns temáticos, que fortalecem laços sociais; publicação de boas práticas no ambiente inovador, ligada a normas e valores de grupo; divulgação de publicações e postagens técnicas e científicas, que geram o capital social cognitivo; apresentação de projetos de inovação social, inspiradores de confiança no ambiente social e editais de geração de oportunidades, que respondem pela geração de capital social a partir de regras de interação.

Esses benefícios, quando desfrutados pela coletividade, produzem valores que são assimilados em grupo, como a confiança na instituição, a percepção de presença institucional, as relações entre os públicos, o surgimento de leis e normas próprias e o novo conhecimento.

O uso dos campos para comentários foi pouco frequente nos sites dos Parques. Apenas $16 \%$ das mídias os disponibilizam. A grande maioria dos sites não oferece o mesmo recurso, mas mais da metade dos sites pesquisados redireciona a interatividade às mídias sociais, utilizando-se de hiperlinks. A escassez ou ausência destes recursos de forma acessível não condiz com a importância da interatividade mútua, que é a comunicação facilitada entre seres humanos para a geração do capital social relacional. A pesquisa apontou que este tipo de

Perspectivas em Gestão \& Conhecimento, João Pessoa, v. 9, n. 2, p. 112-127, maio/ago. 2019. 
capital social suscita intervenções e trocas entre autores e leitores, gerando efeito, inclusive, sobre o capital social cognitivo futuro, o qual se reflete na produção dos novos conteúdos informativos.

Analisando em partes, a maior parte dos sites direciona o usuário para três redes sociais, enquanto $12 \%$ ofertaram links para cinco ou mais redes. No caso do direcionamento aos sites de redes sociais, a interação mútua ocorre fora da página oficial do Parque, mas ele utiliza a ferramenta como extensão de sua presença digital, o que também impacta na geração de capital social. Afinal, os sites de redes sociais são vistos como o campo das interações mútuas entre comunidades de usuários.

Facebook, Twitter e YouTube foram os sites de redes sociais citados com maior frequência. Mas também foi possível identificar falta de atualização no direcionamento feito por alguns sites. Dois parques, por exemplo, disponibilizavam links para a rede social Orkut, extinta pela companhia Google em setembro de 2014, cerca de um ano antes do período da pesquisa. As quebras ou erros de hiperlinks representaram $10 \%$ dos disponibilizados nas homepages pesquisadas.

Ao todo, $37,5 \%$ dos sites com direcionamento para redes sociais não registravam atualização nestas mídias na data da consulta e nos 14 dias anteriores. Tendo como base a efetividade da atualização no intervalo constatado, $90 \%$ dos Parques mantinham o Facebook atualizado e $70 \%$, o Twitter. Se a viabilização da interatividade mútua escolhida pelos Parques é o direcionamento do leitor às mídias sociais, os conteúdos atualizados nestes canais mostram ao leitor a presença digital ativa do Parque, estimulando a troca de informações e a geração de capital social relacional. A atualização de conteúdos, como notícias e vídeos no site dos Parques responde ainda à geração de capital social cognitivo, devido ao apelo informacional que envolve esses conteúdos.

Os Parques devem reconhecer e explorar ambas as formas em benefício da comunicação com seus públicos. Enquanto o capital social cognitivo tende a ir mais longe, alcançando diversas redes pela originalidade e pelo caráter informativo como valores, o capital social relacional se reflete na rápida difusão das informações dentro de uma mesma rede social. Neste caso, o valor está no acesso rápido à informação dentro de uma mesma rede, que internamente compartilha e valida o conteúdo.

Adequar ambientes online de habitats de inovação como os Parques mostra-se essencial para facilitar a comunicação e não apenas obter interações reativas, mas mútuas, envolvendo empresas, universidades, governos, e, acima de tudo, pessoas. Nos sites, a atualização de formatos e conteúdos, abertura à interação mútua, contínuo monitoramento e resposta permitirão aos Parques absorver os benefícios do capital social em suas variações.

No intuito de atualizar o hiato entre a realização e a publicação desta pesquisa, cabe observar que as relações em rede a partir das mídias sociais vêm se alterando rapidamente. Trata-se de um processo evolutivo, sistêmico, previsto ao menos desde que se conheceu a caracterização de web 2.0. O termo foi cunhado por Tim O'Really em 2004, designando o desenvolvimento de aplicativos que aproveitam efeitos da rede para se tornarem melhores pelo uso pessoal, usando a inteligência coletiva (Morais, 2010).

Diante desta evolução, é possível acrescentar que os sites institucionais de Parques e suas homepages há muito deixaram de ser a porta de entrada para o primeiro contato do usuário com conteúdos sobre as instituições. Redes sociais como Facebook, Twitter, Youtube e os próprios motores de busca permitem ao usuário localizar e selecionar conteúdos de interesse de forma mais rápida. Mas os sites de Parques, como referenciais no fomento a uma cultura de inovação, continuam a cumprir funções essenciais como a de endereço, identidade digital, repositório, fonte de comunicação, ambiente de preservação e ponto de partida para a conversão do conhecimento tácito em conhecimento organizacional. 
Após estas constatações, renova-se a validade do estudo e vislumbram-se outras projeções de pesquisa, envolvendo plataformas e conteúdos voltados à inovação em meio à emergência de novas formas de interação e comportamento social originado na web. Cabem neste foco o olhar sobre a comunicação institucional e a chamada internet das coisas (IoT), as atividades de comunicação intensivas no uso do conhecimento, como sistemas de recomendação e curadoria de informações, utilizadas pelos Parques na relação com os seus diversos públicos.

\section{REFERÊNCIAS}

ABDI; ANPROTEC. Parques Tecnológicos no Brasil. estudo, análises e proposições. Brasília, 2008. Acesso em: 20 jan. 2017.

ADÁN, C. El ABC de los parques científicos. Seminarios de La Fundación Española de Reumatología, v. 13, n. 3, p. 85-94, 2012. Disponível em: http://www.elsevier.es/es-revistaseminarios-fundacion-espanola-reumatologia-274-articulo-el-abc-los-parques-cientificosS1577356612000267. Acesso em: 10 jan. 2017.

ARANHA, J. A. S. Incubadoras. In: PAROLIN, Sonia Regina Hierro; VOLPATO, Marcilia (orgs.) Faces do Empreendedorismo Inovador. Curitiba: FIEP - Federação das Indústrias do Estado do Paraná, 2008.

BERTOLINI, S.; BRAVO, G. Social Capital, a Multidimensional Concept. 2001. Disponível em: http://citeseerx.ist.psu.edu/viewdoc/download?doi=10.1.1.197.1952\&rep=rep1\&type=pd f. Acesso em: 10 dez. 2016.

BOYD, D.; ELLISON, N. Social network sites: Definition, history, and scholarship. Journal of Computer-Mediated Communication, v. 13, n. 1, article 11, 2007.

BRASIL. 2016. Lei no 13.243, de 11 de janeiro de 2016. Dispõe sobre estímulos ao desenvolvimento científico, à pesquisa, à capacitação científica e tecnológica e à inovação. Disponível em: http://www.planalto.gov.br/ccivil 03/Ato20152018/2016/Lei/L13243.htm\#art2. Acesso em: 15 nov. 2016.

CASTELLS, M. A Sociedade em Rede. A Era da Informação. 10. ed. Rio de Janeiro: Editora Paz e Terra, 2007.

CASTILHO, C. A. V. O papel da curadoria na promoção do fluxo de notícias em espaços informativos voltados para a produção de conhecimento. Tese (Doutorado em Gestão do Conhecimento) - Universidade Federal de Santa Catarina, 2015. Disponível em: http://btd.egc.ufsc.br/?p=1908. Acesso em: 25 nov. 2016.

DUARTE, J.; BARROS, A.; NOVELLI, A. L. R. Métodos e técnicas de pesquisa em comunicação. São Paulo: Atlas, 2005. 380 p.

ELLISON, N. B. et al. Social network sites: Definition, history, and scholarship. Journal of Computer-Mediated Communication, v. 13, n. 1, p. 210-230, 2007.

Perspectivas em Gestão \& Conhecimento, João Pessoa, v. 9, n. 2, p. 112-127, maio/ago. 2019. 
ETZKOWITZ, H. Hélice tríplice universidade-indústria-governo: inovação em movimento. Porto Alegre: EDIPUCRS, 2009.

FERRARI, M. A.; GASPARINDO, L.; RISOLA, S. A importância dos relacionamentos compartilhados para startups em ambientes de inovação - Estudo de caso do Cietec. In: SEMINÁRIO NACIONAL DE PARQUES TECNOLÓGICOS E INCUBADORAS DE EMPRESAS, 23., 2013. Anprotec, Recife, 14-17 oct, 2013. Disponível em: http://anprotec.org.br/anprotec2014/files/artigos/artigo\%20(6).pdf. Acesso em 20 nov 2016.

FERRARI, P. A força da mídia social: interface e linguagem jornalística no ambiente digital. São Paulo: Factash, 2010.

GOMES, R. A análise de dados em pesquisa qualitativa. In: MINAYO, M. C. S. (Org.). Pesquisa Social: teoria, método e criatividade. Petrópolis: Editora Vozes, 1994. p. 67-80.

HALAVAIS, A. Blogs and the "social weather." Internet Research, v. 3, 2002.

LEMOS, A. Anjos interativos e retribalização do mundo. Sobre interatividade e interfaces digitais. [S.I. S.n], 1997. Disponível em: http://www.facom.ufba.br/ciberpesquisa/lemos/interativo.pdf. Acesso em: 27 nov. 2016.

MORAIS, Felipe. Planejamento estratégico digital: a importância de planejar a comunicação da marca no ambiente digital. Rio de Janeiro: Brasport, 2009.

NONAKA, I.; TAKEUCHI, H. Criação do conhecimento na empresa. Rio de Janeiro: Campus,1997.

NONAKA, I.; TAKEUCHI, H. Teoria da criação do conhecimento organizacional. In: NONAKA, I.; TAKEUCHI, H. (orgs.). Gestão do conhecimento. Porto Alegre: Bookman, 2008.

MCTI, 2014. Estudo de Projetos de Alta Complexidade. Indicadores de Parques Tecnológicos, 2014. Disponível em: http://www.anprotec.org.br/Relata/PNI FINAL web.pdf. Acesso em: 26 nov. 2016.

OUTING, S. What Exactly is 'Interactivity'? Editor \& Publisher News Page. Dezembro, 1998. Disponível em: http://online.sfsu.edu/jkv4edu/INTRO/assignmt/crawford un.pdf Acesso em: 18 nov. 2016.

POLANYI, M. The Tacit Dimension. Chicago: Chicago University Press, 1996.

PRIMO, A. F. T.; CASSOL, M. B. F. Explorando o conceito de interatividade: definições e taxonomias. Informática na Educação: teoria \& prática, v. 2, n. 2, p. 65-80, out. 1999. Disponível em: http://www.iar.unicamp.br/disciplinas/mm educacao/doc/Explorando\%20o\%20conceito\%20d e\%20in.rtf. Acesso em: 16 nov. 2016.

PRIMO, A. Interação mútua e reativa: uma proposta de estudo. Revista da Famecos, n. 12, p. 81-92, jun. 2000.

Perspectivas em Gestão \& Conhecimento, João Pessoa, v. 9, n. 2, p. 112-127, maio/ago. 2019. 
PRIMO, A. Interação mediada por computador: comunicação, cibercultura, cognição. Porto Alegre: Sulina, 2007.

SALAVERRÍA, R., NEGREDO, S. Integrated journalism: Media convergence and newsroom organization. Barcelona: Editorial Sol 90, 2009.

SIMS, R. Interactivity: a forgotten art? 1995. Computers in Human Behavior, 1999.

TEIXEIRA, C. S.; MACEDO, M.; EHLERS, A. C. Benchmarking sobre habitats de inovação no Brasil. Florianópolis: Recepeti. 2015.

TELLES, A. A revolução das mídias sociais: estratégias de marketing digital para você e sua empresa terem sucesso nas mídias sociais, cases, conceitos, dicas e ferramentas. São Paulo: MBooks, 2010.

WOLF, M. Teorias da Comunicação. 5. ed. Lisboa: Editorial Presença, 1999. 